\section{Lean production e riscos psicossociais: o caso de uma fusão multinacional de grupo metalmecânico no Brasil}

\author{
Lean production and psychosocial risks: \\ the case of a multinational merger in a \\ metallurgical company in Brazil
}

\section{Lean production y riesgos psicosociales: el caso de una fusión dentro un grupo metalmecánico en Brasil}

\begin{abstract}
This study focused on the method known as "lean production" as a work-related psychosocial risk factor in a Brazilian multinational auto parts company after its merger with other multinational companies. The authors conducted a qualitative analysis of two time points: the first using on-site observation and key interviews with managers and workers during implementation of lean production in 1996; the second, 16 years later, comparing data from a document search in labor inspection records from the Ministry of Labor and Employment and legal proceedings initiated by the Office of the Public Prosecutor for Labor Affairs. The merger led to layoffs, replacements, and an increase in the workday. A class action suit was filed on grounds of aggravated working conditions. The new production model led to psychosocial risks that increased the need for workers' health precautions when changes in the production process introduced new and increased risks of physical and mental illnesses.
\end{abstract}

Psychossocial Impact; Workers; Occupational Health
Eunice Stenger 1

Maria Inês Monteiro 1

Marcos Oliveira Sabino 2

Isabella de Oliveira Campos Miquilin 1

Heleno Rodrigues Corrêa Filho ${ }^{1}$

\section{Resumo}

Estudamos o método denominado lean production como um dos elementos associados com riscos psicossociais relacionados ao trabalho em empresa multinacional de autopeças após sua fusão com outras multinacionais. Analisamos qualitativamente dois momentos: o primeiro por meio de observação local e entrevistas-chave com gerentes e trabalhadores, quando da implantação do lean production em 1996; o seguinte, confrontando 16 anos mais tarde dados de pesquisa documental em registros de inspeção de condições de trabalho elaborado pelo Ministério do Trabalho e Emprego e procedimentos judiciais iniciados pelo Ministério Público do Trabalho. A fusão implicou demissões, substituições e aumentos da jornada de trabalho. Houve a abertura de Ação Civil Pública suscitada pela piora das condições de trabalho. O novo modelo produtivo trouxe riscos psicossociais que reforçaram a necessidade da precaução em saúde do trabalhador quando mudanças no processo produtivo introduziram novos e maiores riscos de doenças físicas e mentais.

Impacto Psicossocial; Trabalhadores; Saúde do Trabalhador 


\section{Introdução}

O termo fatores psicossociais no trabalho engloba um conjunto de percepções e experiências do trabalhador que podem incluir também condições e ambiente de trabalho. Abrange também influências econômicas e sociais que repercutem sobre o trabalhador. Há estudos que explicitam a natureza e interação entre esses fatores, incluindo a relação com as hierarquias, circunstâncias familiares ou da vida privada e elementos culturais como nutrição, facilidades de transporte e interações com órgãos de poder ${ }^{3,4}$. Mas se são subjetivas as circunstâncias mais gerais, as condições imediatas de trabalho parecem mais percebidas pelos trabalhadores.

Este estudo se insere na Agenda Nacional de Prioridade de Pesquisa em Saúde proposta pelo Ministério da Saúde em 2008, no tópico Impacto da Reestruturação Produtiva sobre a Saúde 1. Lean production 2 , reestruturação produtiva $\mathrm{e}$ produção enxuta são quase sinônimas. Escolhemos o termo lean production por ser o que consta mais nas citações internacionais em saúde.

"La interacción negativa entre las condiciones de trabajo y los factores humanos del trabajador pueden conducir a perturbaciones emocionales, problemas del comportamiento y cambios bioquímicos y neurohormonales que presentan riesgos adicionales de enfermedades mentales $y$ físicas" 5 (p. 5).

O modelo de gestão lean production foi disseminado mundialmente desde o final dos anos 1990, seus mecanismos são definidos por formas mais flexíveis de organização e gestão do trabalho e da produção. Nele foram rearticulados novos (e outros não tão novos) princípios de organização do trabalho, tais como: trabalho em equipe, polivalência, responsabilização coletiva, estabelecimento de metas de produção, redução da linha hierárquica, círculos de qualidade, organização qualificante, grupos de progresso, terceirização. $\mathrm{O}$ alvo do lean era certo desenvolvimento do processo produtivo, tanto nos aspectos do controle da qualidade e produtividade, quanto nos da eficiência e da eficácia. A estratégia da competitividade provoca uma relativa mudança nas relações de produção e de trabalho na medida em que transforma o coletivo de trabalho. No $l e-$ an production, os trabalhadores se transformam em fiscais uns dos outros, comprometidos com a empresa mediante estratégia participativa de cunho patronal, que objetiva resolver as relações e instâncias conflitantes, assim como estabelecer uma esfera coercitiva de consenso e consulta 2,6.

A constante busca por novos modelos produtivos é parte da estratégia do capital por sua própria valorização e expansão. Operando em uma economia de mercado aberta e competitiva, interessa dar conta da concorrência internacional e do elevado grau de incerteza e imprevisibilidade causado pela introdução das novas tecnologias mecânicas (hardware), informacionais (software) e humanas (peopleware) 7. Esses novos processos de gestão emergem e passam a necessitar ainda mais intensivamente da cooperação com o trabalho. É na concepção do trabalho, no modelo organizacional aplicado ao coletivo de trabalhadores e não ao individuo, que ocorre algo que na verdade encobre realidades múltiplas e que ameaça a saúde psíquica dos trabalhadores. 7 .

Os fatores psicossociais podem repercutir sobre os acidentes de trabalho 8,9,10. O anuário estatístico do INSS registrou, entre 2007 e 2009, 36.010 acidentes com Comunicação de Acidente de Trabalho (CAT) no setor de metalurgia, sendo $89 \%$ deles típicos, $7 \%$ de trajeto e $4 \%$, doenças do trabalho 11

Este estudo teve por objetivo identificar riscos psicossociais, por meio de entrevistas (fase 1) e pesquisa documental com base na leitura e interpretação desses materiais (ênfase na ação civil pública do Ministério Público - fase 2). Tais riscos psicossociais de adoecimento são derivados do modelo lean production disseminado nas empresas metalúrgicas de grande porte em finais dos anos 1990 e a partir daí para diversos outros setores 12 .

\section{Metodologia}

Utilizamos uma triangulação de métodos em duas fases com a observação direta e entrevistas-chave na primeira fase, antes da fusão em 1996, combinadas com entrevistas mediadas pelo Departamento Intersindical de Estatística e Estudos Socioeconômicos (DIEESE) aos sindicatos em 1996, com revisitas avulsas em 2004. Na segunda fase (2010-2013), debruçamo-nos em uma análise documental constituída especialmente pelo estudo de uma Ação Civil Pública (ACP) 12,13,14 elaborada nos anos de 2006 e 2012. “A ACP é o meio constitucionalmente assegurado do Ministério Público ao Estado ou a outros entes coletivos autorizados por lei para promover a defesa judicial dos interesses ou direitos difusos (metaindividuais), coletivos e individuais homogêneos" 15 (p. 102-3). A Figura 1 ilustra as duas fases da pesquisa.

Foram realizadas no primeiro ano cinco visitas às linhas de produção da Empresa $\mathrm{A}$, em São Bernardo e Santo Amaro (ABC Paulista), São Paulo, Brasil. Durante as visitas, foram realizadas entrevistas intencionais semiestruturadas com 


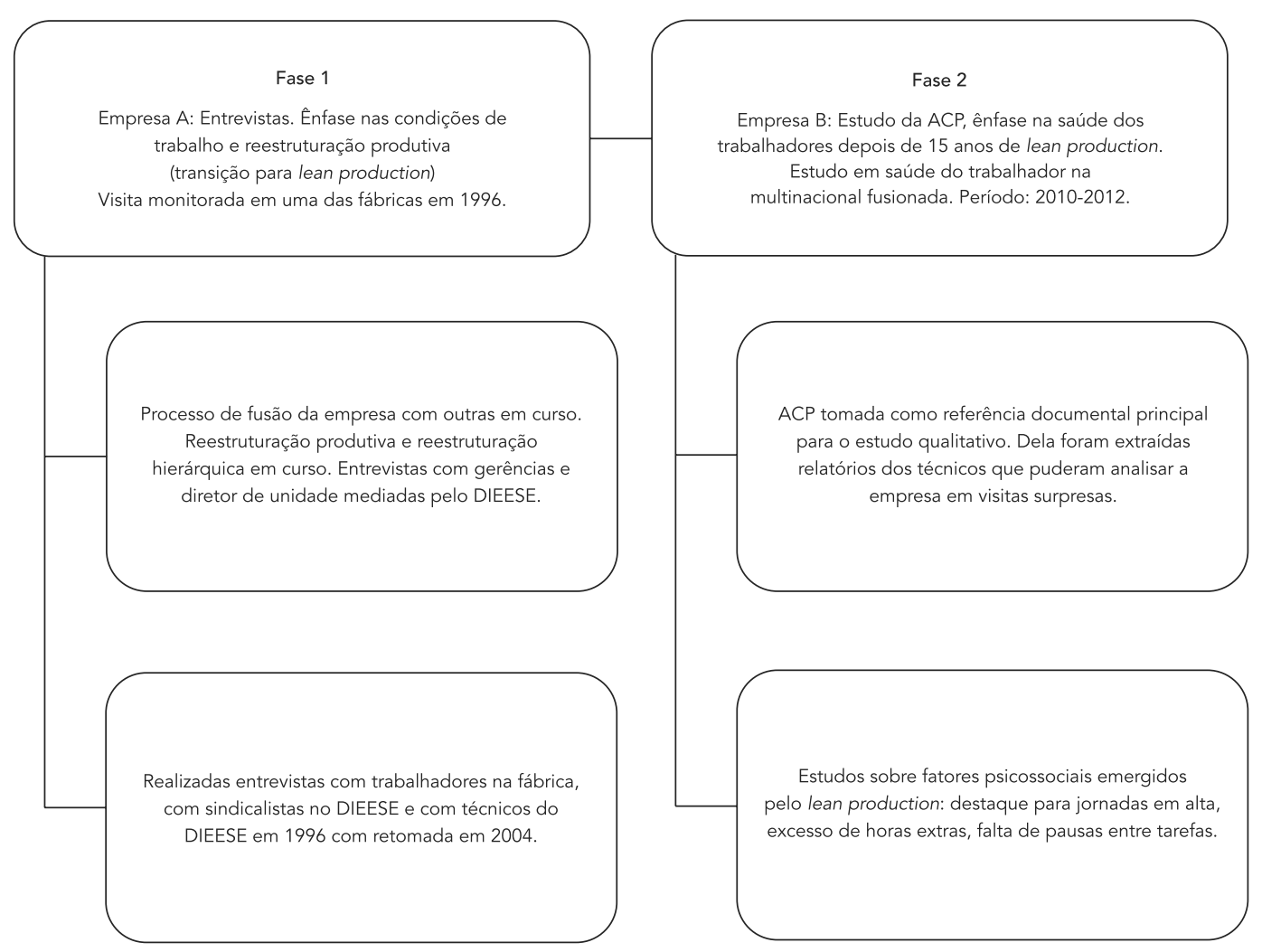

ACP: Ação Civil Pública; DIEESE: Departamento Intersindical de Estatística e Estudos Socioeconômicos.

16 trabalhadores, quatro administradores, quatro dirigentes sindicais e dois diretores; os últimos, em processo de desligamento. As visitas de observação eram precedias por uma explanação da gerência intermediária sobre as atividades realizadas e a forma de produção. Os sujeitos da pesquisa da fase I foram indicados pela gerência da empresa.

Os questionários versavam sobre organização e condições de trabalho e permitiram confronto com os dados levantados anos depois pelo Ministério do Trabalho e Emprego. A primeira lei brasileira sobre consentimento livre e esclarecido (Resolução no 196/96 do Conselho Nacional de Saúde) foi editada posteriormente à realização das visitas. O consentimento verbal implícito por aceitar responder à entrevista foi obtido por intermédio do DIEESE, informando que a entrevista fazia parte de pesquisa acadêmica e que a pesquisadora não tinha vínculo trabalhista com a empresa estudada nem com os sindicatos.
As visitas foram se tornando mais difíceis com a fusão em curso, no entanto foi possível acompanhar aspectos das negociações sindicais da jornada de trabalho, quase sempre circunscritos a questões de modulações da jornada, frequentemente sob a forma de banco de horas, no qual horas extras são compensadas com horas a menos ou a mais segundo a demanda do produto final.

Os documentos do Ministério Público do Trabalho são de livre acesso, porém solicitamos antes autorização para consulta e publicação dos dados (nem todos foram consentidos). As visitas à empresa foram feitas na primeira fase. Na segunda fase, o trabalho documental foi predominante. Os registros de adoecimentos foram feitos pelos técnicos no Ministério do Trabalho e Emprego e tratavam de pedidos de afastamento por razão médica (não houve autorização para publicação dos dados relativos a adoecimentos psíquicos). 
Os processos que tramitaram no Ministério Público do Trabalho foram estudados para identificar condições de trabalho após a fusão que originou a Empresa B, atenção especial foi dada particularmente aos relatos dos peritos do Ministério Público do Trabalho e auditores do Ministério do Trabalho e Emprego, pois elas nos sinalizavam riscos psicossociais que vieram a ser constatados pelos autores, quando foram lidos os processos disponíveis na Procuradoria Regional do Trabalho da 15a Região do Ministério Público do Trabalho (PRT-15) 12,13,14.

Esse longo prazo entre a primeira e a segunda fase da pesquisa permitiu cotejar o modelo produtivo observado em 1996 que já incluía elementos que expunham os trabalhadores a riscos psicossociais (jornadas longas, turnover elevado, insegurança no emprego etc.) e ergonômicos (aglomeração das máquinas e homens na planta da fábrica, ausência de pausas entre tarefas etc.), com possíveis consequências posteriores para a saúde. Primeiramente, identificamos os fatores do modelo produtivo para em seguida analisar os riscos constatados em visitas sem aviso à empresa por auditores do Ministério do Trabalho e Emprego e por procuradores e peritos do Ministério Público do Trabalho na PRT-15 (descrito nos relatórios que constam na $\mathrm{ACP}$ ).

Estudos em saúde do trabalhador, tomando o modelo produtivo como exposição ou como fator psicossocial, são hoje mais frequentes dada a importância da temática, havendo espaço para estudos qualitativos e quantitativos 16,17 .

\section{O trabalho intensificado a partir da fusão: origem dos problemas de saúde?}

A Empresa A produzia autopeças e foi fundada em 1950 quando a soma total de veículos existentes no Brasil, todos importados, não passava de 500 mil unidades, com clientela na indústria automobilística, marítima e aeronáutica. Sua internacionalização se fez a princípio como empresa brasileira de autopeças em 1985, em cidade dos Estados Unidos. Com investimentos crescentes em pesquisa, foi criado um Centro de Tecnologia Avançada e, posteriormente, outro em cidade do Estado da Carolina do Sul (Estados Unidos), inaugurando uma unidade de fabricação de pistões articulados. Em 1991, por intermédio de uma joint-venture com outra empresa americana, foi criada nova empresa subsidiária que passou a produzir também bronzinas e buchas na planta de outra cidade dos Estados Unidos. A necessidade de proximidade maior com os clientes europeus levou a Empresa A a se lançar na construção de uma base europeia na Alemanha.
Até 1996, a Empresa A foi fornecedora do mercado nacional de reposição e fabricante de autopeças, sendo uma das poucas multinacionais brasileiras, e permaneceu até finais dos anos 1990 como a mais importante produtora de autopeças do país, abastecendo $80 \%$ do mercado nacional (todo o restante era importado). Exportava $2 \%$ para os Estados Unidos, América do Sul, Canadá e Alemanha.

A Empresa B correspondia à fusão da Empresa A com mais duas outras e um banco em um processo de financeirização ${ }^{18}$. A inserção internacional pelo sistema lean era obrigatória para a sobrevivência dela como metalúrgica de primeiro nível, pois a partir de então as montadoras automobilísticas mundiais passaram a priorizar uns poucos fornecedores globais (de primeiro nível). Em tais novas circunstâncias, a nova Empresa B fez também investimentos em pesquisa, notadamente na aplicação de diferentes tipos de alumínio. Na pós-fusão, a Empresa B foi responsável em 2004 pela criação de cerca de $35 \mathrm{mil}$ postos de trabalho no mundo, dos quais cerca de 7 mil no Brasil. As montadoras passavam a controlar a concepção do produto e suas dimensões indispensáveis, ficando a geometria da peça ao encargo do fornecedor de primeira linha 7. Em 1996, a Empresa A alterou seu modelo produtivo para lean production 2,6.

Em Santo Amaro, São Paulo, a Empresa A se concentrou na produção de pistões e componentes do motor, o que pressupunha a existência de trabalhadores qualificados para fabricar a peça central do motor com alta confiabilidade. O trabalho acontecia em três turnos fixos, exceto nos setores administrativos. Ainda na Empresa A, foram introduzidas células de produção que reagruparam máquinas interligadas em produções diversas, realizando transferência automática de peças de uma linha de montagem para outra. A empresa criou grupos autônomos que produziam, embalavam, estocavam e distribuíam, de maneira logística, permitindo produzir o máximo com variação de tamanhos de peças, com redução da mão de obra nas diversas etapas industriais (que é o cerne do lean production), conforme explicou o gerente de produção:

"Nas células de alta produtividade, estimamos estar em igualdade em relação aos nossos concorrentes se não estivermos até melhor do que eles. Nossa tecnologia se baseia em um know-how difícil e é um projeto que nós desenvolvemos. Nós estamos em um setor de ponta de desenvolvimento. Temos as células de trabalho destinadas a tamanhos diferentes de produtos. Na mesma linha, nós podemos passar de um produto a outro em função de sua dimensão. Desde 30 milímetros até 150 milímetros. Temos 3.000 produtos diferentes" 
(entrevista gravada com o gerente de produção, 1996).

A variabilidade na linha de produção foi ampliada no lean production 2,6. Ela decorreu do esgotamento do modelo fordista/taylorista (Tabela 1) e fez emergir um novo "paradigma tecnológico" no qual era decisivo ser capaz de responder a um mercado progressivamente mais instável, imprevisível, diferenciado e calcado no uso da microeletrônica. Perseguia-se a flexibilidade dos produtos, processo de trabalho, equipamentos e jornada de trabalho. Produção flexível implicava a reformulação permanente da escala de produção, resultando em grande variabilidade dela. O desafio era manter níveis elevados de produtividade, simultaneamente respondendo à variabilidade e diversificação da demanda.

O impacto deste "paradigma tecnológico" repercutiu em diferentes níveis do sistema industrial geral, particularmente na metalurgia e automobilística. A diversificação dos modelos e ciclos de vida mais curtos dos produtos eram elementos decisivos em face da concorrência em mercados oligopolísticos. Reestruturação e reorganização permanente emergiam como estratégia e condição de sobrevivência num sistema global instável, que implicava mudanças técnicas e tecnológicas, além de alterações nos níveis hierárquicos e instabilidade do emprego, envolvendo trabalhadores e gerencia local. Ocorreu, assim, a integração das funções produtivas tais como pesquisa e desenvolvimento na empresa, acentuando-se o "enxugamento" da hierarquia, visando à obtenção de um fluxo interno de informações mais eficaz, e ampliando a automatização das atividades produtivas.

A busca pelo funcionamento contínuo com máxima utilização de máquinas e equipamentos foi assegurada pela fusão de diferentes jornadas e contratos de trabalho, dificultando a fiscalização pelas Delegacias Regionais de Trabalho e sindicatos. As negociações em data base, via de regra, não tratam da rotação das escalas de trabalho, e também não incluem pausas, de modo diverso ao que acontece em países desenvolvidos.

A demissão sempre temida pelos trabalhadores passou a ser realidade também para níveis hierárquicos mais elevados. A instabilidade no posto, emprego e função se consolida como outro fator psicossocial a ameaçar a saúde coletiva.

\section{Mudanças organizacionais e saúde dos trabalhadores: células de produção e horas extras}

Constatações sobre doenças do trabalho não surgem repentinamente. Os adoecimentos são resultantes de processo contínuo de esforços que vão lesionando o corpo até que a dor e outros sintomas se manifestem, impossibilitando a continuidade do trabalho 19 . O lean production representou para os trabalhadores exposição ao trabalho intensificado, com longas jornadas sob

Principais condições de trabalho nos modelos produtivos.

\begin{tabular}{|c|c|c|}
\hline $\begin{array}{l}\text { Fatores psicossociais em cada modelo } \\
\text { produtivo }\end{array}$ & Taylorismo (contexto: fordismo) & Lean production \\
\hline Peças/Ferramentas e insumos a trabalhar & $\begin{array}{l}\text { Homogêneos. Repetição de gestos e tarefas. } \\
\text { Busca pelo menor movimento }\end{array}$ & Variáveis peças e produtos \\
\hline Produto final do trabalho & Padronizado & Variação segundo demanda \\
\hline Autonomia no trabalho & $\begin{array}{c}\text { Autonomia processual relativa baixa/Média } \\
\text { autonomia em eventos como acidentes }\end{array}$ & $\begin{array}{c}\text { Autonomia na célula de produção/Autonomia } \\
\text { processual/Gestão do risco pela equipe }\end{array}$ \\
\hline Controle do trabalho & Pela hierarquia intermediária (gerência) & Pela célula ou equipe de produção \\
\hline Alternância de tarefas & Nenhuma rotatividade & Grupos polivalentes móveis \\
\hline Trabalho em equipe & $\begin{array}{l}\text { Não, competitividade estabelecida pelo operário } \\
\text { padrão }\end{array}$ & $\begin{array}{l}\text { Sim, grupo de resolução de problemas; grupos } \\
\text { pluridisciplinares; equipes de projeto }\end{array}$ \\
\hline $\begin{array}{l}\text { Gestão do tempo nas tarefas (ritmo de } \\
\text { produção) }\end{array}$ & Cadência imposta pela gerência & Trabalho em just-in-time \\
\hline Estabilidade no emprego & Pela produtividade na tarefa & $\begin{array}{c}\text { Mediante avaliações individualizadas da } \\
\text { produtividade }\end{array}$ \\
\hline Comunicação no trabalho & Não, associado ao fordismo & $\begin{array}{c}\text { Sim, estabelecendo concorrência interpessoal na } \\
\text { célula de produção }\end{array}$ \\
\hline
\end{tabular}


pressões diretas ou subjetivas relacionadas com o registro de lesões diversas posteriores a 1996.

Os acordos coletivos na maior parte das plantas da Empresa B, a partir do final dos anos 1990, previam jornada de trabalho semanal de 40 a 42 horas, variando segundo região instalada. $\mathrm{Na}$ prática, acrescentavam-se horas extras sistematicamente, fato que ampliava a jornada efetiva de trabalho. Na antiga Empresa A, os horários de trabalho se tornaram passíveis de modulação com turnos fixos e três equipes, com horários de início e de saída do trabalho às 14, 22 e 6 horas. As horas extras declaradas nas entrevistas na Empresa A em 1996 eram de até cinco horas por trabalhador, por mês, mas passíveis de omissão. A célula de produção requer organização por turnos e, por vezes, um trabalhador se responsabiliza pela falha de produção do outro, em caso de ausência ou não cumprimento das metas de produção a equipe é penalizada. Investigando questões de ergonomia, o Ministério Público do Trabalho respondeu à ACP de 1999 a 2005 12,14. Um quadro abusivo de horas extras (Tabelas 2, 3 e 4), jornadas de trabalho intensas e mais longas foi registrado.

A alegação das empresas para justificar a imposição de flutuação da jornada de trabalho, por vezes sem pagamento e registro formal, é de que existiria sazonalidade da demanda e conveniências excepcionais dos setores de trabalho. Um auditor do Ministério do Trabalho e Emprego levantou dúvidas sobre essas questões anos depois (2004 e 2005). A Empresa B apresentou análise ergonômica do trabalho feita por um consultor externo de ergonomia, contudo a consultoria externa foi analisada pelos auditores do Minis- tério do Trabalho e Emprego que identificaram número excessivo e persistente de horas extras com jornadas ampliadas. Em um período em que as jornadas de trabalho de vários outros países foram reduzidas, naquela empresa as jornadas foram rearranjadas, com modulações do tipo banco de horas, havendo até ampliação 13.

Documento da ACP aceita com ressalvas o laudo técnico apresentado pela empresa e questiona os efeitos da jornada de trabalho que estariam relacionados a posteriores problemas de saúde entre os trabalhadores. "O exame dos registros de ponto comprovam que os trabalhadores frequentemente entram até 30 minutos antes da jornada e saem até 15 minutos depois, sem que recebam o pagamento da respectiva jornada extra" 13.

A pausa, lacuna do discurso dos sindicatos brasileiros, é enfatizada nas negociações coletivas de diversos países desenvolvidos, como França e Alemanha 20,21. Representantes sindicais e patronais não deveriam firmar acordos que permitam uma empresa deixar de pagar como horas extraordinárias os períodos anteriores ao início ou posteriores ao final da jornada.

Foram analisados os dados do relatório sobre jornada diária de trabalho (cartão de ponto) do período de sete meses entre janeiro e julho de 2004, evidenciando a mediana de 114 horas extras por trabalhador no total dos meses trabalhados ou 16,3 horas-extras por mês. Os trabalhadores realizavam de dez a vinte jornadas diárias contínuas sem dispor de dias de intervalo para descanso (Tabela 3), sendo de um a seis dias por mês; a jornada de trabalho foi maior que dez horas. Essa análise foi feita com base em dados de

Tabela 2

Total de horas extras de trabalho realizadas mensalmente por cada trabalhador no período de janeiro a junho, 2004

\begin{tabular}{|c|c|c|c|c|c|c|c|}
\hline \multirow[t]{2}{*}{ Trabalhador } & \multicolumn{7}{|c|}{ Número de horas extras trabalhadas mensalmente } \\
\hline & Janeiro & Fevereiro & Março & Abril & Maio & Junho & Total \\
\hline A & 32 & 41 & 16 & 24 & - & 48 & 161 \\
\hline B & 16 & 8 & 32 & 16 & - & 16 & 88 \\
\hline C & 32 & 17 & 16 & - & - & 40 & 105 \\
\hline$D$ & 15,5 & 19,5 & 16 & 29 & 40 & 26 & 146 \\
\hline$E$ & 19,5 & 16 & 28 & 44,5 & 66,5 & 49 & 223,5 \\
\hline $\mathrm{F}$ & 26 & 39 & 11 & 16 & 31 & 16 & 139 \\
\hline G & 11,5 & 16 & 32 & 11,5 & 31,5 & 16 & 118,5 \\
\hline $\mathrm{H}^{*}$ & - & - & - & - & - & 43 & 43 \\
\hline I & 8 & - & 12 & - & - & - & 20 \\
\hline
\end{tabular}

* Admitido em 17 de maio de 2004.

Fonte: Ministério Público Estadual de São Paulo 12. 
Número de dias trabalhados de forma contínua sem descanso semanal no período de janeiro a julho, 2004.

\begin{tabular}{lccccccc}
\hline Trabalhador & \multicolumn{7}{c}{ Número de dias trabalhados sem descanso semanal } \\
& Janeiro & Fevereiro & Março & Abril & Maio & Junho & Julho \\
\hline A & 13 & 13 & $12 / 12$ & - & - & 13 & - \\
B & - & 8 & $12 / 13$ & - & - & - & - \\
C & 13 & 13 & $12 / 12$ & - & - & - & - \\
D & - & - & 12 & - & - & - & - \\
E & 12 & - & 13 & - & - & 19 & 13 \\
F & 12 & 12 & 12 & 10 & 10 & $11 / 12$ & - \\
G & - & - & 13 & - & - & - & - \\
$H^{*}$ & - & - & - & - & - & - & - \\
I & - & - & - & - & - & - & - \\
\hline
\end{tabular}

* Admitido em 17 de maio de 2004.

Fonte: Ministério Público Estadual de São Paulo 12

Tabela 4

Número de dias em que cada trabalhador realizou jornada de trabalho acima de dez horas, no período de janeiro a julho, 2004.

\begin{tabular}{|c|c|c|c|c|c|c|c|}
\hline \multirow[t]{2}{*}{ Trabalhador } & \multicolumn{7}{|c|}{ Número de dias em que as jornadas de trabalho ultrapassaram dez horas } \\
\hline & Janeiro & Fevereiro & Março & Abril & Maio & Junho & Julho \\
\hline A & - & - & - & - & - & - & \\
\hline B & - & - & - & - & - & - & - \\
\hline C & - & - & - & - & - & - & - \\
\hline$D$ & 3 & 1 & 3 & 1 & - & 1 & - \\
\hline$E$ & 1 & - & 1 & 6 & - & 1 & - \\
\hline $\mathrm{F}$ & 2 & 2 & 2 & - & 2 & - & - \\
\hline G & - & - & - & - & - & - & - \\
\hline $\mathrm{H}^{*}$ & - & - & - & - & - & 1 & - \\
\hline 1 & - & - & 1 & 1 & - & 1 & 1 \\
\hline
\end{tabular}

* Admitido em 17 de maio de 2004

Fonte: Ministério Público Estadual de São Paulo 12.

nove trabalhadores selecionados pelos auditores do Ministério do Trabalho e Emprego 13.

Acordos coletivos patronais e sindicais permitiram que, por vezes, na Empresa B a carga horária fosse prolongada de 42 para 46 horas semanais (1998) com trabalho adicional aos sábados, mediante comunicação com uma semana de antecedência, utilizando horas "devidas pelos trabalhadores" por dias ou horas paradas em épocas de baixa demanda. Esse recurso de se dever ou ser credor de horas de trabalho para atender à demanda flutuante, foi denominado no Brasil de "banco de horas". As horas extras trabalhadas e não pagas são meramente somadas, aumentando-se dias de folga ou acréscimo no período de férias.

Horas extras podem resultar de pressão da demanda sazonal, ou podem ser usadas para amortecer ineficiências organizacionais: atrasos, excessos de refugos e produção não programada. Todavia, se o uso abusivo de horas extras não for eliminado, haverá menos contratações e mais sobrecarga de trabalho (na Empresa B, 800 pessoas deixaram de ter emprego por conta do excesso de horas extras). A legislação brasileira não dificulta a flexibilidade das cargas horárias e as empresas podem utilizar diversos contratos individuais e formas de gestão, executar demis- 
sões em massa, impor férias coletivas e aumentar o tempo de produção, alegando flutuação na demanda. A questão das horas extras é polêmica até entre os trabalhadores, muitos as defendem por ser uma via para obter complemento salarial e não se lembram de que elas impedem a geração de novas vagas de emprego. A legislação permite "flexibilidade para cima" e possibilita que os trabalhadores ultrapassem em até duas horas por dia a sua jornada, com adicional de $50 \%$ por hora adicional. Em médio prazo, criam um problema estrutural, visto que menos empregos formais e mais desigualdade são criados entre trabalhadores qualificados. Elas desequilibram ainda a negociação coletiva e terão impacto na saúde por elevarem o risco de acidentes de trabalho.

Discrepâncias de salários em nível internacional também ampliam as desigualdades. Os sindicatos relataram que para uma mesma função o trabalhador recebia US\$ 3 no Brasil e US\$ 22 na Alemanha 22. Deve ser destacado que o turnover (relação entre demissões e contratações) gira em torno de 3,6\% ao ano no Brasil, sinalizando a alta vulnerabilidade do emprego 22 . O elevado turnover desfavorece a qualificação, condição que nem sempre beneficia a empresa porque vai contra a polivalência dos trabalhadores e pressupõe alguma estabilidade e conhecimento do trabalho local (chão de fábrica).

Quanto às negociações em torno das jornadas no Brasil, pouco avanço favorável aconteceu para os trabalhadores da Empresa B, comparativamente à indústria automobilística brasileira nos anos 1990 e, menos ainda, comparadas ao contexto internacional 21. Fato é que a flexibilidade avançou sem que os sindicatos obtivessem contrapartida real em termos de redução da jornada. Em 2003, em um ambiente de forte recessão interna, a fusão foi consumada, o processo de trabalho foi intensificado e a evolução da distribuição de horas extras foi desfavorável aos trabalhadores na Empresa B. Em 2004, a jornada menor entre as plantas brasileiras da empresa foi de 40 horas e a maior de 42 , entretanto horas extras foram omitidas.

A mudança gerencial e tecnológica alterou a rotina dos trabalhadores e introduziu diferentes métodos "japoneses" de organização do trabalho. Um gerente de recursos humanos $(\mathrm{RH})$ relatou ter tido resultados imprevisíveis com os Círculos de Controle de Qualidade (CCQ), o que ele atribuiu à dificuldade de adaptação cultural. É sensato pensar que o trabalho que inclui alta exigência de confiabilidade possa ser conciliado com alta rotatividade do trabalho? É possível haver alta performance mediante ameaça de desemprego? São compatíveis gestão participativa, alta rotatividade e a necessidade de produzir com alta qualidade? Essas questões enfrentadas pelos trabalhadores e sindicatos incomodavam também a gerência. Um gerente argumentou que no Japão a introdução do controle estatístico de processo precedeu os CCQ e trouxe bons resultados em termos de melhorias do processo interno. Em nossas entrevistas identificamos afirmações da gerência que afirma que o sistema participativo possibilitava aos trabalhadores abrir espaço para reivindicações por melhores condições de trabalho, mas o tornou rapidamente descartado, prevalecendo a tradição autoritária das empresas.

\section{Problemas de saúde resultantes da intensificação do trabalho}

A intensificação do trabalho na Empresa B criou condições que repercutiriam sobre a saúde dos trabalhadores. Na Empresa B, no período 20042005, os dados produzidos pelo Ministério do Trabalho e Emprego, consultados no Ministério Público do Trabalho ${ }^{13}$, descreveram as jornadas. Foram constatados riscos à saúde enfrentados pelos trabalhadores por motivos relacionados à ergonomia, proteção de máquinas, exposição ao calor, ruído e duração da jornada de trabalho.

É fato que as células substituíram a linha de montagem: produção e insumos não são mais homogêneos como foram no fordismo. A variação de pesos e peças no processo de produção rompe talvez a monotonia da tarefa, mas emerge como importante novo fator de risco para as lesões por esforços repetitivos - doenças osteomusculares relacionadas ao trabalho (LER/ DORT) 23. O Ministério do Trabalho e Emprego alerta para a intensificação do trabalho presente nas células de produção com a virtual eliminação das férias anuais e das pausas no trabalho. Indica que o processo de degradação do trabalho foi aumentado pela Empresa B, que além de intensificar o trabalho o agravou com as operações "gargalo", que por sua complexidade ou dificuldade, requerem maior tempo para execução que as tarefas que as antecedem, trazendo acúmulo e pressão, resultando em riscos de LER/DORT para esses operadores 14 .

Na inspeção judicial realizada em 2004 junto com a análise documental, os auditores do Ministério do Trabalho e Emprego alertavam quanto aos riscos à saúde para problemas posturais e ergonômicos que provocariam casos de LER/ DORT 14.

Embora a empresa tenha introduzido rodízios em algumas atividades nas células de produção de usinagem de pistões, houve pequena diferença nos movimentos realizados e não fo- 
ram implantadas em todas as atividades que se constituíram em postos de maior risco para LER/ DORT. Os rodízios foram medida preventiva, porém pouco foi realizado em termos de pausas, importantes para a recuperação do corpo.

Esgotados em suas forças pela ausência de férias, agravadas pela falta de pausas na produção, os trabalhadores caminhavam para um processo de alta demanda com acúmulo de exposição e desgaste laboral. A diminuição do grau de controle exercido pelos trabalhadores no processo produtivo aumentava o risco de acidentes 24,25. Nas negociações não se tratava da duração e rotatividade das escalas de trabalho e também não incluíam as pausas, de modo diverso ao que ocorria em países desenvolvidos 20 .

Os técnicos do Ministério do Trabalho e Emprego e do Ministério Público do Trabalho lamentam que os trabalhadores não tenham recebido orientações corretas sobre como prevenir o adoecimento por causas ocupacionais ligadas à intensificação do trabalho como a LER/ DORT. É imprescindível que o trabalhador saiba dos fatores de risco e medidas de controle, não apenas no momento de sua admissão, mas também periodicamente, com trabalho de informação e observação insistente das atividades de risco, orientando o uso e ajuste das ferramentas, bancadas, cadeiras, apoios, entre outros. Nesse sentido, destacam os técnicos do Ministério do Trabalho e Emprego e do Ministério Público do Trabalho, seria fundamental que as chefias dos diversos níveis estivessem treinadas, conscientes e participantes, identificando as situações de risco e vigiando para que as medidas de controle fossem adotadas, garantindo desse modo que os rodízios e pausas fossem realizados. Os relatos sindicais denunciam abusos 22 .

"Éelevada a incidência de Lesões por Esforços Repetitivos (LER). Em Indaiatuba há comentários sobre a existência de 40 empregados afastados do trabalho por motivo de doença, o que representaria $10 \%$ do contingente. As causas para esse grande número de casos de LER seriam várias: falta de ergonomia nos postos de trabalho, movimentação de pesos excessivos, má postura no trabalho em função dos equipamentos e ritmo de trabalho acelerado. Além disso, a adoção de conceitos da produção enxuta (NA: lean production) se traduziu no aumento do número de máquinas a serem operadas por um único trabalhador. Até recentemente, as falhas na operação eram motivo de advertências por parte das chefias, o que só deixou de ser feito depois que a CIPA se posicionou contrariamente. Esse tipo de pressão por produção é amplificada pelo temor da perda do emprego. Soma-se a isto a exigência de qualidade e baixo nivel de refugo, o que acaba pondo de lado a saúde e segurança dos operários" 13 (grifos nossos).

Jornadas longas no setor da metalurgia aparecem também associadas aos adoecimentos psíquicos 26,27, frequentemente negado, sugerindo a necessidade de utilização do Nexo Técnico Epidemiológico Previdenciário 28, com identificação dos acidentes e doenças do trabalho. Análise do ramo de atividade econômica da metalurgia baseada em dados de 2000 a 2008 evidenciou vinculação mais intensa com risco de adoecimento mental e neurológico, o que pode ser considerado evidência nacional indireta resultante da implantação desses métodos produtivos 28 .

As medidas relativas à reorganização do trabalho para torná-lo menos nocivo à saúde têm caráter preventivo insuficiente se não adotadas no seu conjunto. Precisam ser sistematizadas, sinalizadas e supervisionadas por chefias, Serviços de Segurança e Medicina do Trabalho (SESMT) e Comissões Internas de Prevenção de Acidentes (CIPAS), para garantir a obrigatoriedade do seu cumprimento. Ainda que a prevenção às LER/ DORT fosse considerada prioritária, não era prática sistemática dentro da Empresa B.

Em 1996, a Empresa A introduziu o lean production e iniciaram os casos de afastamento na Empresa B. Os turnos de revezamento junto com jornadas com muitas horas extras são preocupantes, já que nos relatórios da Empresa B para a Justiça do Trabalho, na ACP do Ministério Público do Trabalho, constava a análise dos anos de 1996 a 1998, anos em que a intensificação do trabalho foi maior 12. A Empresa B tentou convencer o Judiciário e o Ministério Público do Trabalho, assumindo como pausas a soma de "micropausas", ou seja, tentou passar como pausas intervalos de tempo que ocorriam entre uma tarefa e outra, condição que não é considerada suficiente para permitir a recuperação adequada das estruturas do corpo ligadas ao movimento. $\mathrm{O}$ Ministério do Trabalho e Emprego concluiu então que o relato da empresa era deficiente porque não considerava diversos fatores de riscos relacionados à organização do trabalho como jornada real de trabalho, frequência e intensidade de horas extras, ritmo de trabalho e de produção. Medidas preventivas por parte da empresa não constam ou não eram sistemáticas. À Empresa B foi solicitado estudo que identificasse as queixas dos trabalhadores, que permitisse intervenção ergonômica preventiva e corretiva, recusando-se a emitir CAT. O ocorrido na Empresa B foi captado também como realidade do setor metalúrgico.

"Há 240 empregados afastados por motivo de doença ocupacional, principalmente LER. A empresa não adota a rotação de tarefas e, nesta unidade, nem sequer é feita ginástica laboral. En- 
quanto isso, a CIPA é considerada pouco atuante, pela presença de muitos membros com cargos de chefia. Em São Bernardo do Campo, os sindicalistas estimaram em $10 \%$ os empregados com sintomas de LER. (...) O tema da ergonomia dos postos de trabalho está ausente das discussões entre Sindicato e empresa, não havendo soluções conjuntas... Quadro semelhante se verifica em Mogi Guaçu, onde a maioria desses casos teria sido notificada oficialmente pelo sindicato (emissão da Comunicação de Acidente de Trabalho - CAT), já que a empresa não assume que a doença seja causada pelo trabalho na fábrica. Este é um aspecto importante, pois revela a conduta da empresa, que só 'abre uma CAT' em casos de acidentes, não o fazendo em casos de doença ocupacional. Ela opta por levar os problemas para a esfera judicial no sentido de tentar provar que não há nexo causal entre o trabalho e a doença" 13.

Questão de gênero registrada na Empresa B: nas diferentes fábricas da Empresa B em São Paulo não havia mulheres operárias. $\mathrm{O}$ diretor de $\mathrm{RH}$ sugeriu dificuldades com os sindicatos locais, sublinhando que em outras plantas da empresa no Rio de Janeiro havia participação feminina com bons resultados. Para ele, as mulheres teriam mais dificuldade em São Paulo por causa das escalas rotativas, inexistentes no Rio de Janeiro, nas quais realizavam trabalho noturno sem resistência dos sindicatos. A interpretação do gerente denuncia precarização do trabalho maior no Rio de Janeiro que em São Paulo, ou aponta existência de outra estratégia sindical, pois, se por um lado a garantia de acesso ao trabalho na empresa era ampla, por outro, as conquistas paulistas não valiam para os trabalhadores do Rio de Janeiro. Nessa perspectiva a pluralidade sindical tende a não estender as conquistas de melhorias nas condições de trabalho, contradição que assusta: criar emprego com redução do amparo à saúde.

A representação sindical no Brasil é estabelecida por base geográfica territorial delimitada para cada ramo de atividade. Os sindicatos aderem a diferentes centrais sindicais, o que faz diferentes representações sindicais coexistirem em uma mesma empresa com plantas dispersas pelo país. Este quadro de pluralidade traz consequências complexas no que se refere à visibilidade $\mathrm{e}$ proteção da saúde ainda vulnerável dos trabalhadores em multinacionais no Brasil.

\section{Considerações finais}

As condições de trabalho com adensamento de máquinas e homens na planta da Empresa B, as ausências de pausas durante as jornadas de trabalho, as longas jornadas de trabalho (com inclusão insistente de horas extras), a pressão de trabalho relacionada à produção just-in-time $\mathrm{e}$ a sobrecarga de tarefas relatadas pelos autores, caracterizam uma situação de trabalho intensificado e em condições ergonômicas desfavoráveis.

O trabalho sob condições de pressão por metas e qualidade é por si mesmo fator estressor porque é um trabalho exercido em situação de alerta, podendo levar ao esgotamento físico e psíquico. Na ACP, por mais que esteja documentada a jornada excessiva (horas extras e falta de pausas), houve conciliação. A contradição principal está no fato de que horas extras, além de acarretar sobrecarga à saúde dos trabalhadores, leva a empresa a deixar de criar empregos (estimativas do Ministério Público do Trabalho é de que 800 trabalhadores deixaram de ser contratados no perídodo estudado).

Os trabalhadores conseguiram cumprir com as exigências para obtenção dos certificados de qualidade da International Organization for Standardization (ISO), o que permitiu à empresa permanecer como fornecedora de primeiro nível. A Empresa B na Alemanha, como já dito, pratica jornadas muito inferiores às de sua planta no Brasil onde ela paga menos por hora e utiliza muito mais horas extras.

Enfim, a produtividade elevada não tem sido convertida em melhores condições de trabalho e de saúde dos trabalhadores estudados. A utilização abusiva de jornadas longas gera desemprego e persiste como um dos componentes peculiares e nefastos do lean production no Brasil. Pouco se avançou na promoção e proteção da saúde do trabalhadores, se é que não se retrocedeu. Pesquisas que usam o Nexo Técnico Epidemiológico Previdenciário que versa sobre o adoecimento físico e psíquico dos trabalhadores na metalurgia poderão dar mais transparência a uma política ciente da realidade brasileira. 


\section{Resumen}

Estudiamos el método llamado lean production como uno de los elementos asociados con riesgos relacionados con el trabajo en una empresa multinacional de autopartes, después de su fusión con otras multinacionales. Analizamos cualitativamente dos momentos: el primero por observación local, y entrevistas clave con directores y trabajadores, cuando se produjo la implantación del lean production en 1996; el siguiente, 16 años más tarde, comparando datos de investigación documental en registros de inspección de las condiciones de trabajo hechas por el Ministerio del Trabajo y Empleo y también procedimientos judiciales iniciados por el Ministerio Público del Trabajo. La fusión implicó despidos, sustituciones y aumentos de las jornadas de trabajo. Se inició un procedimiento sancionador público, debido al empeoramiento de las condiciones de trabajo. El nuevo modelo productivo acarreó riesgos psicosociales que aumentaron la necesidad de prevención en salud del trabajador, cuando los cambios en el proceso productivo introducen nuevos y mayores riesgos de enfermedades físicas y mentales.

Impacto Psicosocial; Trabajadores; Salud Laboral

\section{Colaboradores}

E. Stenger idealizou as fases I e II, realizou visitas, entrevistas, coleta documental, análise e redação do artigo. M. I. Monteiro colaborou na estruturação da fase II do projeto, na análise e redação do artigo. M. O. Sabino contribuiu na condução da fase II do projeto, coleta de dados documentais, análise, e redação do artigo. I. O. C. Miquilin colaborou na redação do artigo. H. R. Corrêa Filho orientou a elaboração da coleta e análise da fase II, participou da discussão e redação do artigo.

\section{Agradecimentos}

Agradecemos à Capes pelas bolsas concedidas. À Professora Letícia Marín-León pelas várias contribuições na revisão do texto. Agradecemos ao Departamento Intersindical de Estatística e Estudos Socioeconômicos (DIEESE).

\section{Referências}

1. Ministério da Saúde. Agenda nacional de prioridades de pesquisa em saude Brasília: Ministério da Saúde; 2011.

2. Womack J, Jones DT, Roos D, Carpenter DS. Le système qui va changer le monde: une analyse des industries automobiles mondiales dirigée par le Massachusetts Institut of Tecnology. Paris: Éditions Dunod; 1992.

3. Kompier MA. New systems of work organization and workers' health. Scand J Work Environ Health 2006; 32:421-30.

4. Chouanière D. Stress et risques psycosociaux: concepts et prévention. Paris: Institut National de Recherche et de Sécurité pour la Prévention des Accidents du Travail et des Maladies Professionnelles; 2006. (Documents pour le Médecin du Travail, 106).

5. Organización Internacional del Trabajo. Factores psicosociales en el trabajo: naturaleza, incidencia y prevención. Geneva: Organización Internacional del Trabajo; 2009.

6. Kochan TA, Lansbury RD, MacDuffie JP. After lean production: evolving employement practices in the word auto industry. Ithaca: ILR Cornell University Press; 1997.
7. Cardoso LA. Grupo de Trabalho 18: sindicalismo e política após fordismo e sindicalismo: elementos para uma discussão dos novos modelos produtivos. In: XXIV Encontro Anual da Associação Nacional de Pós-graduação e Pesquisa em Ciências Sociais - ANPOCS. http://portal.anpocs.org/ portal/index.php?option=com_docman\&task= doc_view\&gid=4872\&Itemid=357 (acessado em 01/ Jan/2012).

8. Garcias F, Dalmasso C, Sardas J-C. Les determinants socio-psychologiques de la santé au travail: modèles d'analyse et action sur l'organisation. In: XXIIe Congrès de l'AGRH. http://www.reims-ms. fr/agrh/03-publications/01-actescongres.html? query=congr\%E8s\&search=1 (acessado em $01 / \mathrm{Jan} /$ 2013).

9. Heaney CA, Israel BA, House JS. Chronic job insecurity among automobile workers: effects on job satisfaction and health. Soc Sci Med 1994; 38:1431-7.

10. Wünsch Filho V. Reestruturação produtiva e acidentes de trabalho no Brasil: estrutura e tendências. Cad Saúde Pública 1999; 15:41-52. 
11. Ministério da Previdência Social. Anuário estatístico da previdência social. Brasília: Ministério da Previdência Social; 2009.

12. Ministério Público Estadual de São Paulo. Inquérito Civil no 56/99. PAJ no 143.1999.15.000/5-05 (volume I do anexo I) relativo à Ação Civil Pública trabalhista relativa ao meio ambiente de trabalho no 0008500-34.1999.5.15.0071. Campinas In Ministério Público do Trabalho. Campinas: Procuradoria Regional do Trabalho da 15a Região; 1999.

13. Ministério do Trabalho e Emprego. Processo SDT 47.998-07.502/04-81. Solicitação de renovação da autorização para redução do intervalo para repouso ou alimentação. Auditoria fiscal do trabalho e emprego, em 25 de agosto de 2005. Campinas: Procuradoria Regional do Trabalho da 15a Região; 2005.

14. Tribunal Regional do Trabalho da 15a Região. Processo TRT15: 8500-34-1999-0071. Considerações sobre os documentos apresentados pela Mahle em inspeção judicial e audiência/JT, de 09 de novembro de 2004 - SDT 47.998-02.148/03-18, registrado na PRT15/MPT em 11 de março de 2005 relativo à Ação Civil Pública - ACPn0008500-34. 1999.5.15.0071. http://consulta.trt15.jus.br/consul ta/owa/pProcesso.wListaProcesso?pTipoConsul $\mathrm{ta}=$ PROCESSOCNJ\&pArgumento $1=0008500 \& \mathrm{pAr}$ gumento2 $=34 \&$ pArgumento3=1999\&pArgumen to4=0071 (acessado em 01/Jan/2013).

15. Leite ACB. Ação Civil Pública na perspectiva dos direitos humanos. São Paulo: LTr Editora; 2008.

16. Bernardo M. Trabalho duro, discurso flexível: uma análise das contradições do toyotismo a partir da vivência de trabalhadores. São Paulo: Editora Expressão Popular; 2009.

17. Valeyre A. Conditions de travail et santé au travail des salariés de l'Union Européene: des situations contrastées selon les formes d'organisation. Paris : Centre d'Etudes de l'Emploi; 2006.
18. Du Tertre C. Lean production et modèles de valeur: une approche régulationniste par le travail. Activités Revue Eletronique 2012; 9(2). http:// www.activites.org/v9n2/v9n2.pdf.

19. Marklund S, Bolin M, von Essen J. Can individual health differences be explained by workplace characteristics? A multilevel analysis. Soc Sci Med 2008; 66:650-62.

20. Thoemmes J. Vers la fin du temps de travail. Paris: Presse Universitaire de France; 2000.

21. Thoemmes J.L'évolution d'une règle d'organisation sur dix ans: l'accord collectif chez un constructeur d'automobiles en Allemagne. Sociologie du Travail 2008; 50:219-36.

22. Instituto Observatório Social. Relações de trabalho e condições de trabalho no Grupo Mahle Brasil. http://www.observatoriosocial.org.br/arqmorto/ download/mahle_dez2005port.pdf (acessado em 01/Mar/2012).

23. Kompier M, van der Beek AJ. Psychosocial factors at work and musculoskeletal disorders. Scand J Work Environ Health 2008; 34:323-5.

24. Siegrist J. Effort-reward imbalance at work and cardiovascular diseases. Int J Occup Med Environ Health 2010; 23:279-85.

25. Karasek R. Job demands, job decision latitude, and mental strain: implications for job redesign. Adm Sci Q 1979; 24:285-309.

26. Harma M. Are long workhours a health risk? Scand J Work Environ Health 2003; 29:167-9.

27. Kleppa E, Sanne B, Tell GS. Working overtime is associated with anxiety and depression: the Hordaland Health Study. J Occup Environ Med 2008; 50:658-66.

28. Oliveira PRA. Nexo Técnico Epidemiológico Previdenciário (NTEP), Fator Acidentário de Prevenção (FAP): um novo olhar sobre a saúde do trabalhador. 2ạ Ed. São Paulo: LTr Editora; 2010.

Recebido em 01/Abr/2013

Versão final reapresentada em 24/Out/2013

Aprovado em 15/Jan/2014 